\title{
FRAGMENTOS DE UNA COSMOVISIÓN MESTIZA ASOCIADA AL ACCESO Y USO DEL ENTORNO COSTERO EN EL ARCHIPIÉLAGO DE CHILOÉ*
}

\author{
FRAGMENTS OF A MIXTURE COSMOVISION ASSOCIATED ACCESS \\ AND USE OF COASTAL ENVIRONMENT IN THE ARCHIPELAGO CHILOÉ
}

\author{
Ricardo Álvarez Abel y Francisco Ther Ríos $^{* *}$
}

\begin{abstract}
Este artículo evidencia fragmentos de una cosmovisión asociada a poblaciones costeras del Mar Interior de Chiloé, cuyos orígenes se remontan a intensos procesos de mestizaje hispano-indígena. Dicha cosmovisión se advierte, principalmente, a partir del análisis de entrevistas etnográficas en las provincias de Llanquihue, Chiloé y Palena, en sus zonas archipielágicas. Los fragmentos observados corresponden a prácticas asociadas a sistemas tradicionales de administración local que aplicaban las poblaciones para acceder a los espacios costeros y hacerse de especies alimenticias, en una época en la que abundaban las especies marinas. La desaparición reciente de esta cosmovisión costera está vinculada tanto con la instalación de la empresa privada a inicios de los años ochenta como también con las regulaciones del Estado a partir de los noventa. El efecto de dicha transformación se traduce hoy en una escasez de especies, en conflictos entre humanos, y en problemas medioambientales sin que se visualicen soluciones a corto y mediano plazo.

Palabras claves: Sistemas tradicionales de administración local, conflictos litorales, borde costero, aspectos culturales de la gestión litoral, Chiloé.

This article shows fragments of evidence associated with coastal populations Interior Sea of Chiloé worldview, whose origins date back to intense processes of Spanish-Indian fusion. This worldview is seen mainly from the analysis of ethnographic interviews in the provinces of Llanquihue, Chiloé and Palena in its archipelagic areas. The observed fragments correspond to practices associated with traditional systems of local government that applied populations to access coastal areas and made of food species, in an era in which abundant marine species. The recent disappearance of this coastal worldview is linked both to the installation of private enterprise in the early eighties, as with state regulations from the nineties. The effect of this transformation is reflected today in a shortage of species, human conflict, and environmental problems without solutions in the short and medium term are displayed. ment, Chiloé.

Key words: Traditional systems of local government, coastal conflicts, seaboard, cultural aspects of the coastal manage-
\end{abstract}

\section{Introducción}

Siguiendo a Andrade et al. (2008), las normas jurídicas asociadas al borde costero en Chile se refieren a diversos términos, como aguas interiores, borde costero, fondo de mar, río o lago, franja de playa a cuyo uso tienen derecho los pescadores, línea de base normal, línea de playa o línea de más altas mareas, mar territorial y mar presencial, playa de mar, porción de agua, terreno de playa y Zona de Protección Costera ${ }^{1}$.

El actual proceso de zonificación de la Región de Los Lagos ha definido 11 usos preferentes para el territorio costero regional; asociándose nueve de estos usos al archipiélago de Chiloé: i) Zona de caletas pesqueras, ii) Zonas urbanas menores, iii)
Zonas urbanas mayores, iv) Zona portuaria turística, v) Zona de conectividad estratégica, vi) Zona de protección ambiental, vii) Zona para la pesca artesanal, turismo y protección ambiental, viii) Zona para pesca artesanal y turismo, ix) Zona para pesca artesanal, turismo y acuicultura bajo restricciones. No obstante, existiendo reglamentaciones e instituciones públicas en Chiloé existen permanentes tensiones respecto de dos o más distintas racionalidades o lógicas que no han logrado vincularse para potenciar un desarrollo territorial. En Chiloé todas las comunas son costeras, sin embargo los planes vigentes de Desarrollo Comunal (PLADECO) no incluyen proyecciones acerca de los usos futuros posibles en el borde costero, y menos respecto de la integración de aspectos culturales al desarrollo

\footnotetext{
* $\quad$ Resultado del proyecto FONDECYT No 1121204.

** Universidad de Los Lagos, Programa ATLAS. Osorno, Chile Correos electrónicos: taijataf@gmail.com; fther@ulagos.cl
} 
del borde costero. De los usos preferentes para el territorio costero regional, en la provincia de Chiloé nos encontramos frente a un proceso de concentración de la base productiva en la actividad salmonera, donde las decisiones de las empresas se toman a un nivel global, siendo el territorio local el que se ve afectado. Las transformaciones pasan fundamentalmente por decisiones estatales-centrales y empresariales-globales que escapan a la capacidad local. Así, el estudio del borde costero de Chiloé resulta un caso particularmente interesante de abordar, debido a los múltiples cruces económicos, ambientales y culturales que han ocurrido a lo largo de su historia.

\section{Desde los tiempos de una cosmovisión costera hasta a la negación actual del mestizaje}

Se ha hecho frecuente hoy asociar el concepto de cosmovisión a demandas territoriales-identitarias de pueblos originarios. Ello, pues representa el más profundo sentido de pertenencia de dichas poblaciones para hacer efectivo un proyecto de re-habitar lo que fue usurpado, principalmente durante la República, o la conformación del Estado-Nación de Chile. La utilización de este término se enfrenta de golpe con una racionalidad occidental extremadamente afiatada durante un largo proceso histórico y, por sobre todo, tras décadas de modelo neoliberal, lo que provoca reacciones diversas desde la sociedad civil y Estado, pues no logra dicha propuesta dialogar con un discurso sustentado en el llamado "desarrollo productivo". La palabra cosmovisión es, por tanto, frecuentemente desvalorada y mirada como una curiosidad dentro de las discusiones sobre el destino final de los espacios habitados. Por sobre todo, sigue estando asociada exclusivamente a los pueblos originarios en el imaginario colectivo $y$, contradictoriamente, considerada un elemento ajeno de quienes no forman parte de dichos pueblos. Lo medular del caso es que el modelo neoliberal, y el efecto histórico del posicionamiento efectivo del Estado, han logrado desmembrar lo que antes estaba integrado. A propósito de aquello, las observaciones realizadas en el archipiélago del mar interior de Chiloé revelan un mundo altamente complejo y mestizado, en el que difícilmente se podía separar, hasta hace pocas décadas, componentes originarios de hispanos. Las últimas décadas (sobre todo tras el terremoto de 1960 y el posterior mejoramiento vial de la Región) han logrado instalar, hasta en las zonas más aisladas e insulares de Chiloé marítimo, al Estado y la industria acuícola, y tras ello, la desarticulación de un modo de vida que efectivamente se sostenía en cosmovisiones locales.

Los corrales de pesca, entre otras prácticas locales observadas en el mar interior de Chiloé, evidencian a comunidades costeras ligadas a sistemas tradicionales de administración local, a partir de ellas se mantenía un acceso a los espacios marinos y a las especies recolectadas-capturadas. Estas prácticas territoriales, intrínsecamente adheridas al sistema de creencias locales, cotidianamente se ponían en juego en festividades y actividades productivas, siempre de carácter colectivo. En su conjunto, estas prácticas eran orientadas por ritualidades que otorgaban al mar y a los seres no humanos la calidad de sujetos que podían afectar, positiva o negativamente, al sistema costero local. Se advertía, entonces, una transición ritualizada entre lo terrestre y lo marino, siendo utilizados algunos elementos agropecuarios para rendir tributo al o la mar, y viceversa (Skewes et al. 2012). Es una constante en los relatos etnográficos advertir que las acciones negativas (o insustentables) hacia el mar y las especies marinas traerían consigo escasez. Esto obligaba a los humanos a comportarse adecuadamente. Esta escasez no era necesariamente causada por sobreexplotación, sino por la decisión del mar, o la mar, como sujeto que juzgaba a los humanos.

Por el contrario, el modelo actual de explotación, principalmente extractivo, respaldado por el Estado, considera medidas de control para no sobreexplotar especies comerciales (sin éxito), sin que exista espacio alguno para consideraciones cosmogónicas o, más aún, ritualidades asociadas a prácticas ancestrales. El hecho de que las acciones entre humanos y no humanos sea hoy crítica (así como entre los propios humanos compitiendo por espacios y por especies), coincide con las advertencias antiguas: ¿por qué es importante plantear esto? La desaparición de dichas prácticas antiguas se acomoda temporalmente con el incremento de conflictos entre humanos, y de humanos con el entorno (vivo y no vivo) (Ingold 2012) hasta el grado de hacerse imposible actualmente -en el caso del entorno marino- un ordenamiento costero de las acciones humanas. Lo que antes tenía un carácter de "sujeto" es tratado hoy como "objeto". Finalmente, las alternativas para acceder a los espacios marino-costeros se sustentan en la competencia entre pares (esto incluye-incluso-a las solicitudes 
de espacios costeros marinos de pueblos originarios, denominadas ECMPO). Todo ello deriva en que no solo evidenciamos que la pérdida de una o más cosmovisiones costeras coincide con conflictos que no logran superarse, sino además que la desaparición del carácter mestizo del ser comunitario costero influye, pues lo que se ha superpuesto es un modelo de identidad, ser y hacer trasplantado desde el centro del país, muy afín con el propio modelo neoliberal y con las demandas del Estado por generar poblaciones dependientes.

El aprendizaje apunta a que no puede sustentarse un proceso de ordenamiento de usos del borde costero solamente en aspectos técnicos, sino también en aspectos que el modelo neoliberal ha truncado y estigmatizado, como lo festivo, lo cosmogónico y lo identitario. El hecho de que las poblaciones costeras chilotas (pertenecientes a pueblos originarios o no) coincidieran en ello hasta hace pocas décadas, implica que existía una cosmovisión compartida, heredada de procesos históricos conflictivos pero mestizados finalmente, y de un tiempo mucho más antiguo, asociado a un mestizaje regional previo Williche-Canoero, y también de un macroterritorio que podríamos denominar "Amerindio" (Grebe et al. 1972; Quintero-Montilla 2009), o más bien, Americano. Es esta plataforma la que implica que encontremos relaciones de parentesco entre humanos y no humanos, sustancia basal para que el comportamiento de los primeros sea cuidadoso para con los segundos.

Otro aspecto relevante en torno a la existencia de esta cosmovisión en la zona costera del mar interior de Chiloé está en el modo en cómo desapareció. Sabemos que hasta la primera mitad del siglo XX la utilización de corrales de pesca (Figura 1) implicaba la aplicación de un rito denominado treputo, el que era dirigido por un chamán. Hacia la segunda mitad del siglo, y hasta la década de 1970, estos chamanes desaparecieron, lo que implicó que la práctica ritual se transfiriese a las familias como responsables de su aplicación, generándose una diversificación de estas manifestaciones y -paulatinamente- un aislamiento entre sí, se debilitaron las relaciones de parentesco y, con ello, los elementos puestos en práctica junto a los modos de hacer, hasta que finalmente desapareció (Álvarez et al. 2008). Persiste aun, escasamente, en algunos lugares del mar interior de Chiloé, asociado a artes de pesca como espineles y redes. El objetivo de su aplicación era facilitar la captura de peces por medio de un procedimiento que era bien evaluado por el, o la mar, y las especies; se capturaban especies por medio de acciones colectivas, festivas (alegres) y ceremoniosas.

Acerca de este modo de pescar, sustentado en una cosmovisión que se fragmentó hasta el olvido, se superpuso una normativa estatal cuyo modo de castigar la infracción está basada en el derecho positivo y en la penalización: ya no de la naturaleza hacia los humanos, sino de los humanos sobre los humanos.

\section{Etnografía de las oralidades}

\section{Fragmentos de una cosmovisión en el borde costero de Chiloé insular}

Hasta la década de 1970 se advierten reminiscencias aisladas, pero activas, de una cosmovisión costera mestiza en Chiloé insular. Ello se visibiliza, por ejemplo, mediante relatos en los que se advierte la práctica de un rito, llamado treputo o trepute, y que implicaba hasta mediados del siglo XX el oficio de una persona a quien se le asignaba la denominación de curioso, chaumán, o pougtén (rol de chamán), quien dirigía la ceremonia, hablando para dicha ocasión en lengua veliche (mapudungun) aun cuando sus oyentes no la comprendiesen, con el objetivo de facilitar las tareas de pesca de comunidades costeras (Álvarez et al. 2008: 152). En este caso debemos destacar el rol de este chamán al “(...) regular las relaciones de los hombres con numinoso, es decir, el universo de lo mistérico y sagrado" (Moulián 2002: 42). La pesca y recolección requería de procedimientos cosmogónicos que estaban indisolublemente ligados al habitar humano y su supervivencia colectiva. En dicha ceremonia se ahumaban las artes de pesca (antiguamente, corrales de pesca) con plantas

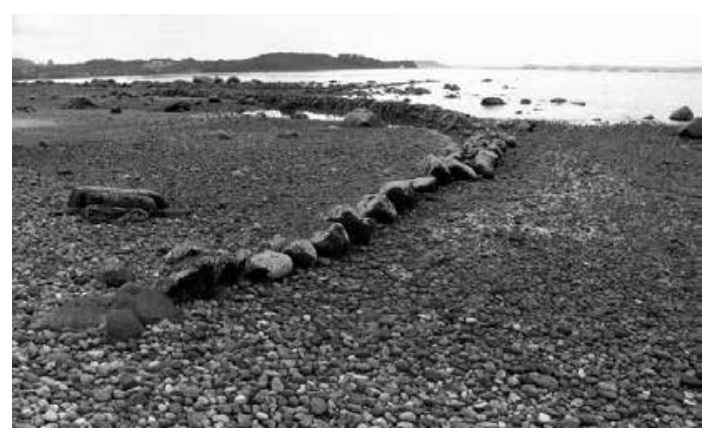

Figura 1. Corral de pesca en Ilque, comuna de Calbuco, provincia de Llanquihue, con marea baja (Fotografía: Ricardo Álvarez 2010). 
aromáticas percibidas colectivamente como plantas con propiedades mágicas, las que eran azotadas contra dichos elementos, a la vez que se enterraban objetos en la playa como productos hortícolas, juguetes de niños, perfume de hombre, e incluso se amarraban lagartijas que luego quedarían sumergidas a manera de ofrenda viva (Álvarez et al. 2008: 152-153). En Cucao incluso sabemos de la aplicación de dicho rito sobre el propio pescador.

Otro aspecto importante de estas reminiscencias radica en los aspectos normativos involucrados, como la necesidad de compartir lo capturado más allá de la propiedad familiar del arte de pesca, lo que implicaba en los hechos que la redistribución de la pesca incluía a un amplio territorio colindante (Skewes et al. 2012); y de los tabúes asociados a la actividad pesquera, como la censura al uso de objetos metálicos en el pescador, los que eran mal vistos por el o la mar (en tanto sujeto); extraer más de lo debido; entrar al mar con perros, o que una mujer embarazada ingresase a mariscar, entre otros muchos factores (FONDECYT 1121204). La aproximación hacia el mar buscaba advertir al propio elemento, como sujeto que era afectado por los humanos positiva o negativamente, y que afectaba a los humanos de igual forma; y no como objeto simplemente utilitario a la vida de los humanos.

\section{Fragmentos materiales de una forma de interactuar con el entorno}

Hoy los paisajes del borde costero revelan el notorio impacto de la industria acuícola, obras viales y otras modificaciones que ocurren en paralelo a una vigorosa migración rural-urbana. En este contexto moderno está pronunciadamente marcada la división entre lo terrestre y lo marino, ambos entornos normados de manera independiente. Por el contrario, en los tiempos del treputo, el acceso al mar se realizaba de manera transicional, no como una fusión, sino como una yuxtaposición de dos contrarios que se encuentran con el diálogo ritual (Grebe et al. 1972: 49). La imagen de isla Apiao en el 2004 (Figuras 2, 3 y 4) muestra un patrón de uso agropecuario que luego se transfiere al intermareal por medio de los corrales de pesca. En uno se criaban animales y se cultivan plantas terrestres, y en el otro se capturan peces y se recolectan mariscos. Tanto

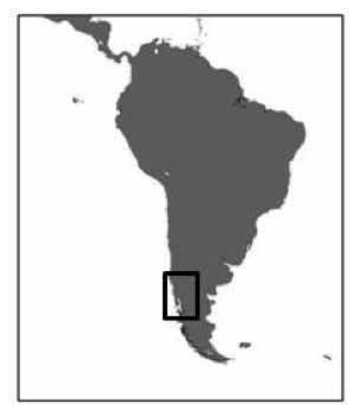

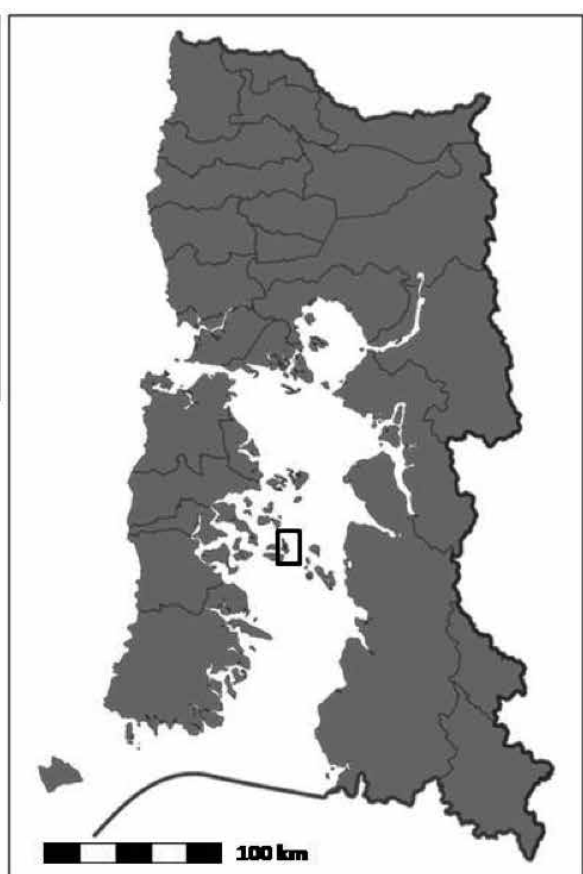

Región de Los Lagos.

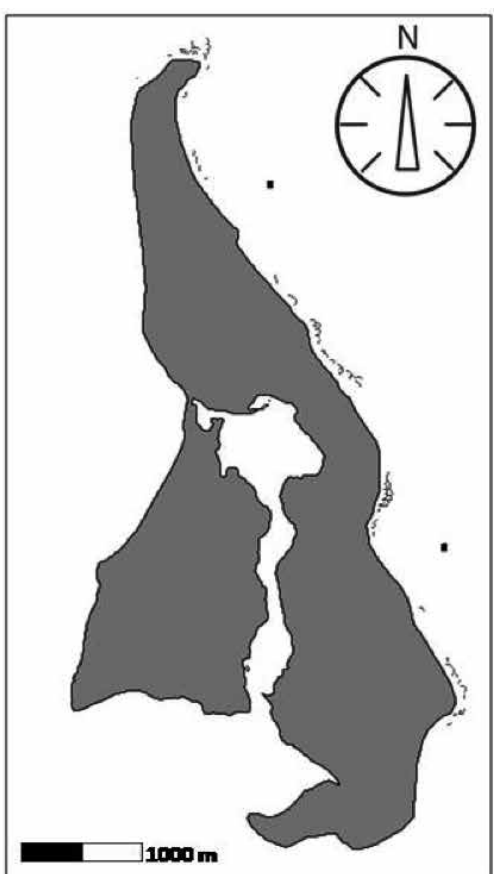

Isla Apiao. Costa $\mathbf{E}$ muestra disposición de corrales de pesca.

Figura 2. Isla Apiao, comuna de Quinchao, provincia de Chiloé, Región de Los Lagos. En su borde costero E se aprecian un sinnúmero de corrales de pesca que demuestran una utilización diferencial del intermareal (Imagen: Ricardo Álvarez 2015). 


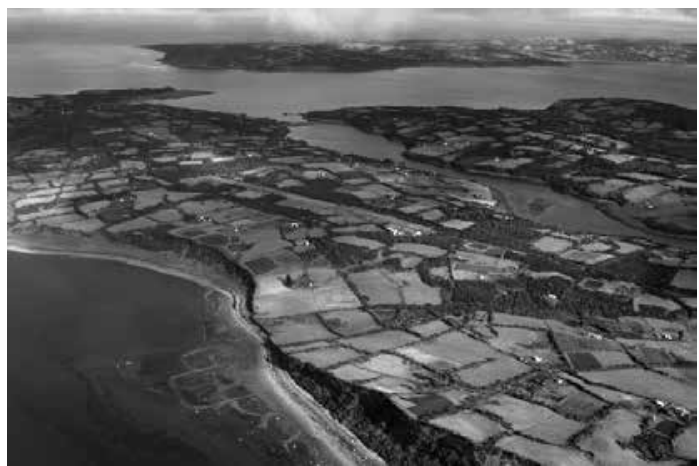

Figura 3. Costa E de isla Apiao. En el extremo inferior izquierdo se aprecia un conjunto de corrales de pesca (Fotografía: Bartulín 2004).

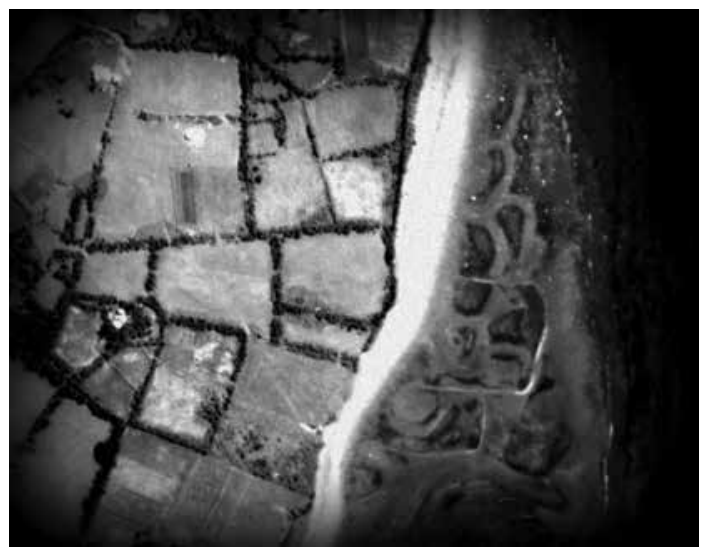

Figura 4. Costa E de isla Apiao. Se observa una regularidad en la modificación del paisaje tanto terrestre como intermareal. Imagen modificada de Google earth @

los primeros como los segundos eran fomentados en su productividad utilizando elementos del mar en la tierra, y viceversa (Skewes et al. 2012). En su conjunto, los rasgos materiales dan cuenta de un patrón común que modificó el paisaje en el pasado y que se manifiesta hasta el presente. Este espacio de apariencia especular replantea la relevancia del intermareal como entorno habitado, imbricado, con elementos terrestres y marinos, y como lugar en el que se conservan materialmente modos de vida que en la práctica han desaparecido.

Dicho espacio no solo demuestra corrales de pesca, sino un sinfín de otros elementos materiales que insisten en torno a modos de habitar invisibilizados pero aún presentes. Los relatos que manifiestan esta época de treputo también dejaron rastros materiales que son posibles de discriminar en el intermareal, elementos que hoy son, en su mayoría, destruidos o incluso negados por la racionalidad moderna, aun cuando estén protegidos, paradójicamente, como sitios arqueológicos por la Ley de Monumentos Nacionales 17.288. La presentificación del pasado en el borde costero ha construido un paisaje mestizo que es respaldado con restos de una cultura material que aún persiste, resistiendo el oleaje del tiempo.

\section{Fragmentos de un abandono: el caso de isla Apiao}

La isla de Apiao (42 $35^{\prime} 57^{\prime}$ 'S $\left./ 73^{\circ} 12^{\prime} 11^{\prime \prime} \mathrm{W}\right)$ se ubica en la comuna de Quemchi, provincia de Chiloé, Región de Los Lagos; esta isla se encuentra separada de su cabecera comunal en al menos 28 $\mathrm{km}$ (Achao, isla Quinchao), y posee $31 \mathrm{~km}$ lineales de borde costero. Resalta en ella un conjunto de corrales de pesca confeccionados con cantos rodados (alrededor de 11 estructuras muy juntas en la Figura 3), de alrededor de 66 corrales de pesca instalados básicamente en su costa Este (Figura 1). Estas estructuras, si bien pertenecían a familias propietarias, permitían la captura de grandes volúmenes de peces que beneficiaban a muchas otras familias que no tenían propiedad directa sobre el lugar, principalmente, mediante mecanismos de redistribución solidarias (Skewes et al. 2012). Sabemos que hacia el 2004 la isla Apiao contaba con 682 personas (Bartulín, CNA 2004). El 60\% de sus habitantes se dedicaba en ese momento a labores agropecuarias y de pesca-recolección de orilla, manteniendo un patrón de vida de campesinado costero afín con la historia mestiza de la zona, sin que ello se tradujese en ingresos monetarios. Esto implicaba un régimen de autosustento alimenticio y de alta dependencia de las redes sociales locales. La generación de dinero adicional se lograba con la recolección temporal de algas (principalmente luga, Gracilaria), lo que involucraba a casi $30 \%$ de sus habitantes. El 5\% de la población representaba a pescadores artesanales formalizados, $3 \%$ a buzos mariscadores formalizados, y $3 \%$ a operarios de salmoneras asalariados (Bartulín, CNA 2004. Figura 5). El 90\% de sus habitantes vivía con menos de \$ 100.000 mensual (Bartulín, CNA 2004. Figura 6). Esto implica que, a pesar de corresponder a un período en el que la salmonicultura, y acuicultura en general, llevaba décadas transformando la Región, esta isla (al igual que casi todas las otras) seguía manteniendo un patrón de vida antiguo, correspondiente con 


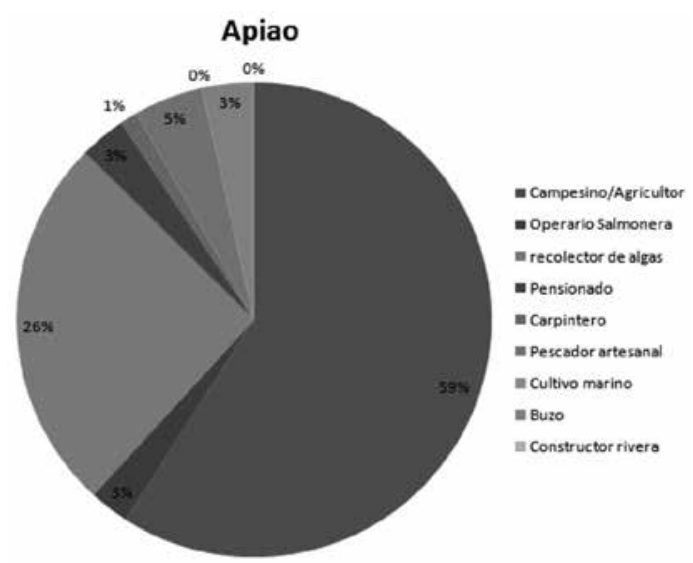

Figura 5. Oficios presentes en isla Apiao hacia 2004 (Imagen: Fondecyt 1121204).

los registros materiales que se observaban en el intermareal y con la oralidad que daba cuenta de las prácticas ritualizadas sobre el acceso al mar y sus especies. Por tanto, la pregunta en la actualidad sería: la transformación productiva extractivista implementada en dichos territorios $i$ es coherente con este modo de habitar?, ¿es posible que bajo dichas condicionantes su implantación sea, por sobre todo, destructiva? Es insólito agregar como agente actual de transformación los ejercicios de fichaje social efectuados por el Estado con el fin de beneficiar a quienes se evidencian más alejados de la estructura de oportunidades. Estas herramientas, como sabemos, fuerzan la visibilización de los elementos negativos que posee cada habitante con el fin de ser favorecido por bonos y otros aportes estatales. Mientras más se invisibilizan los recursos propios -y más se exacerban las precariedades-mayores beneficios se obtendrán del Estado. El impacto de ello ha sido facilitar aún más el abandono de estrategias locales de vida en pro de acercarse a los beneficios del Estado, lo que ha implicado en corto tiempo fenómenos sociales como emigración, transformación hacia labores asalariadas, y abandono de los modos antiguos de vida (incluyendo cosmovisiones).

\section{Conclusión: necesidad de enriquecer culturalmente las políticas ligadas al uso y acceso del borde costero}

La idea de visibilizar la existencia de una cosmovisión costera, extinta en la práctica pero aun vigente, cosmovisión también fragmentaria en la memoria oral y en rasgos materiales, radica en la

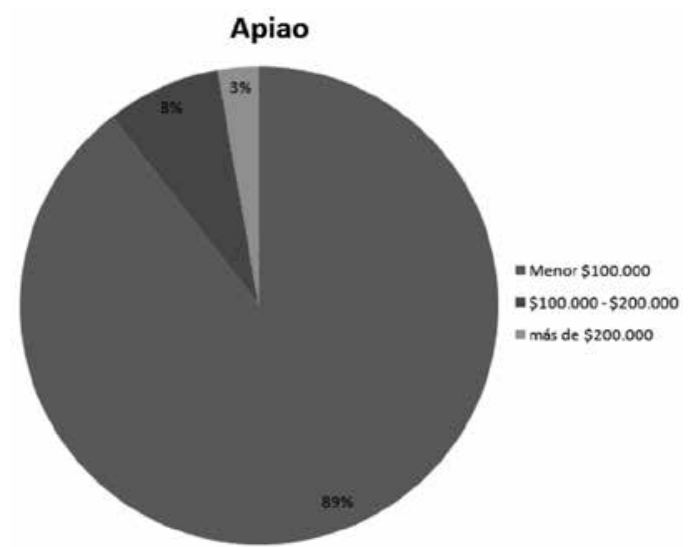

Figura 6. Capacidad de gastos mensuales de población de isla Apiao hacia el 2004.

necesidad de replantearse las estrategias de ordenamiento que actualmente consideran el entorno marino costero, como la Estrategia de Desarrollo (2009-2020), el Plan los Lagos (2010-2014), el Plan Regional de Infraestructura y Gestión del Recurso Hídrico (al 2021). Dichas regulaciones se basan actualmente en aspectos estrictamente técnico-legales, dirigidos por el Estado con escasas variaciones entre un extremo y otro del país, y cuya matriz se sustenta en la competencia por espacios explotables y recursos con fines extractivistas y acuícolas: el mar es objeto. Esto ha generado una crisis socioambiental que demuestra que este modelo no funciona y requiere una transformación significativa, pues ha generado inequidad en aumento entre humanos y un creciente daño en los ambientes y especies utilizadas. Los modos antiguos de habitar y de convivir con el borde costero se sustentaban en prácticas fuertemente ligadas a aspectos cosmogónicos, hoy en día relegados discursivamente a demandas de Pueblos Originarios, pero que formaron parte de lo que llamamos, para Chiloé archipielágico, los tiempos del treputo. Esto es, formaban parte de la sociedad costera más allá de sus vinculaciones identitarias, y repercutían en la práctica en un modo de interacción naturalezahumanos que hoy denominamos sustentable.

El mestizaje negado por la sociedad chilena ¿contiene elementos que son invisibilizados intencionalmente por el modelo neoliberal? ¿Es posible que las futuras normativas integren aspectos cosmogónicos? Un error grave sería incorporarlas a través de orientaciones técnicas y su formalización restringida a decisiones tecnocráticas, pues su 
naturaleza estaba sostenida en acuerdos de carácter local y oral, dinámicos en el tiempo, y cuya fuerza radicaba en las redes sociales desde una perspectiva solidaria y no competitiva. Estos elementos, que parecieran dispersos y no vinculados, son fragmentos que deben recomponerse, dignificándolos, valorizándolos y actualizándolos. Hoy en día quienes aplican a escondidas ramas de plantas aromáticas ahumadas a sus artes de pesca, aun guardan una ética humana que respeta su entorno y a los seres no humanos.

\section{Agradecimientos}

Este artículo se enmarca en el Proyecto FONDECYT 1121204. Agradecimientos especiales a David Núñez, por sus largos recorridos etnográficos por las islas junto a su hijo Cahuel; a Magdalena Navarro, por haber hecho lo mismo años atrás; al equipo del Programa Atlas de la Universidad de Los Lagos; y por sobre todo, a las familias que viven y resisten en las islas guardando este valioso tesoro oral.

\section{Referencias Citadas}

Andrade, Belisario, Arenas, Federico, \& Guijón, Rodrigo 2008 Revisión crítica del marco institucional y legal chileno de ordenamiento territorial: el caso de la zona costera. Revista de Geografía Norte Grande (41), 23-48.

Álvarez, R., Munita, D., Fredes, J. y Mera, R. Corrales de pesca en Chiloé. Imprenta América, Valdivia.

Álvarez, R. y Navarro, M.

2010 Informes usos consuetudinarios de Chiloé. CBA-WWF.

Bartulín, D.

2004 Encuesta suministro eléctrico, Islas Provincias de Palena, Chiloé y Llanquihue. Comisión Nacional de Energía.

Byron, J.

1955 El naufragio de la fragata Wager. Editorial Zig-Zag. Chile.

Cárdenas, R. y Hall, K.

1989 Chiloé, manual de pensamiento mágico y la creencia popular. Ed. El Kultrún. Chile.

Cárdenas, R., Montiel, D. y Hall, K. 1991 Los chono y los veliche de Chiloé. Ed. Olimpo. Chile.

Cavada, F.

1914 Chiloé y los chilotes. Imprenta Universitaria. Chile.

Emperaire, J.

1963 Los nómades del mar. Editorial Universitaria. Chile.

Hucke-Gaete, R., Lo Moro, P. y Ruiz, J.

2010 Conservando el mar de Chiloé, Palena y Las Guaitecas. Imprenta América, Valdivia.

Ingold, T.

2012 Culture, nature et environnement. Traces, 22, 169-187.

Grebe, M., Pacheco, S. y Segura, J.

1972 Cosmovisión Mapuche. Cuadernos de la realidad nacional, $\mathrm{N}^{\circ} 14$, pp. 46-73.
Moraleda, J.

1888 Exploraciones geográficas e hidrográficas de José de Moraleda i Montero. Imprenta nacional. Chile.

Moulián, R.

2002 Magia, retórica y cognición. Un estudio de casos de textos mágicos y comunicación ritual. Lom Ediciones, Santiago de Chile.

Plath, O.

1973 Arte tradicional de Chiloé. Cuaderno de divulgación $\mathrm{N}^{\circ}$ 3. Publicación del Museo de Arte Popular Americano. Universidad de Chile, Fac. Bellas Artes. Chile.

Skewes, J., Alvarez, R. y Navarro, M.

2012 Usos consuetudinarios, conflictos actuales y conservación en el borde costero de Chiloé insular. Magallania, Vol 40(1) 107-123.

Ther, F., Saavedra, G., Álvarez, R., Muñoz, J.

2013 Proyecto FONDECYT 1121204 "Geoantropología de los imaginarios del Mar Interior de Chiloé: itinerarios de temporalidades y apropiaciones socioculturales marítimas".

Urbina, R.

1983 La periferia meridional indiana. Chiloé en el siglo XVIII. Ediciones universitarias de Valparaíso. Chile.

Urbina, $\mathrm{X}$.

2009 La frontera de arriba en el Chile colonial. Ediciones universitarias de Valparaíso. Chile.

Weber, A.

1903 Chiloé, su estado actual, su colonización, su porvenir. Imprenta Mejía. Chile. 
